\title{
EFEKTIVITAS KELOLA PERIKANAN ADAT DALAM MENJAGA STATUS KESEHATAN TERUMBU KARANG DI TELUK MAYALIBIT, RAJA AMPAT
}

\section{EFFECTIVENESS OF CUSTOMARY FISHERIES MANAGEMENT ON MAINTAINING REEF HEALTH STATUS IN MAYALIBIT BAY, RAJA AMPAT}

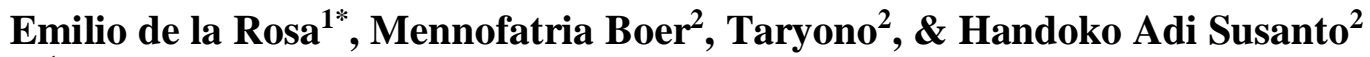 \\ ${ }^{1}$ Program Studi Pengelolaan Sumberdaya Pesisir dan Lautan, Sekolah Pascasarjana, \\ IPB University, Bogor, 16680, Indonesia \\ ${ }^{2}$ Departemen Manajemen Sumberdaya Perairan, Fakultas Perikanan dan Ilmu Kelautan, \\ IPB University, Bogor, 16680, Indonesia \\ *E-mail: edlr91@gmail.com
}

\begin{abstract}
Territorial Use Rights for Fisheries-Reserve (TURF-Reserve) is a form of rights-based fisheries management that could improve the effectiveness and coral reef conservation efforts in Marine Protected Area (MPA). Maya Tribe Customary Council with Mayalibit Bay customary communities declared Customary Fisheries Management (CFM), a fishery resources management approach that combines customary marine tenure, traditional ecological wisdom, and TURF-Reserve principles. This study aims to measure coral reef health conditions to illustrate CFM's effectiveness in maintaining coral reef conditions in Mayalibit Bay. This study uses Point Intercept Transect (PIT) and fish belt transect as data collection methods to gather coral reef health data. Coral reef condition is measured using five indicators with ecological thresholds. Study results show that there is an increase of reef fish biomass and herbivore fish biomass proportion compared to previous condition which indicate a healthy coral reef ecosystem. Decreasing macroalgae: hard coral ratio along with fished: unfished ratio compared to previous condition indicate coral reef ecosystem with moderate condition. This study concluded that the coral reef ecosystem in Mayalibit Bay is in healthy condition and its reef fisheries activities are still considered sustainable. Based on the healthy coral reef condition, CFM is shown as an effective approach in maintaining coral reef ecosystem condition, complementing conservation efforts, and reef fishery resources management in Mayalibit Bay.
\end{abstract}

Keywords: coral reef, Customary Fisheries Management, Mayalibit Bay, Raja Ampat, TURF-Reserve

\begin{abstract}
ABSTRAK
Territorial Use Rights for Fisheries-Reserve (TURF-Reserve) adalah salah satu bentuk dari pendekatan pengelolaan sumber daya perikanan berbasis hak yang dapat meningkatkan efektivitas dan upaya konservasi ekosistem terumbu karang di kawasan konservasi perairan (KKP). Dewan Adat Suku Maya dan masyarakat adat di Teluk Mayalibit mendeklarasikan Kelola Perikanan Adat (KPA), suatu bentuk pengelolaan sumber daya perikanan yang mengombinasikan hak ulayat laut, kearifan ekologi tradisional, dan prinsip-prinsip TURF-Reserve. Tujuan penelitian ini adalah mengukur kondisi kesehatan ekosistem terumbu karang untuk melihat efektivitas KPA dalam menjaga kondisi ekosistem terumbu karang di Teluk Mayalibit. Penelitian ini menggunakan metode Point Intercept Transect (PIT) dan transek sabuk ikan untuk mengumpulkan data kesehatan terumbu karang. Kondisi ekosistem terumbu karang diukur menggunakan lima indikator dengan ambang batas ekologi. Hasil penelitian menunjukkan adanya peningkatan nilai biomassa ikan karang dan proporsi biomassa ikan herbivor dari kondisi sebelumnya, hal ini mengindikasikan ekosistem terumbu karang yang sehat. Nilai rasio makroalga: karang keras hidup serta rasio fished: unfished yang menurun jika dibandingkan dengan kondisi sebelumnya mengindikasikan ekosistem terumbu karang yang berstatus moderat. Berdasarkan hasil analisis, disimpulkan bahwa ekosistem terumbu karang di Teluk Mayalibit masih berada dalam kondisi yang sehat dan aktivitas perikanan karang masih terkendali di dalam batas yang mendukung kelestarian. Hal ini memberikan indikasi bahwa KPA masih efektif dalam menjaga kondisi ekosistem terumbu karang dan membantu upaya konservasi serta pengelolaan sumber daya perikanan karang di Teluk Mayalibit.
\end{abstract}

Kata kunci: Kelola Perikanan Adat, Raja Ampat, Teluk Mayalibit, terumbu karang, TURF-Reserve 


\section{PENDAHULUAN}

Salah satu upaya pengelolaan untuk melindungi ekosistem terumbu karang adalah melalui pembentukan Kawasan Konservasi Perairan (KKP), namun, seringkali KKP berkurang efektivitasnya karena tidak melibatkan masyarakat lokal, khususnya nelayan skala kecil (small-scale fishers), yang hidup di dalam KKP dalam upaya pengelolaan sumber daya perikanan karang (Claudet et al., 2011; Jentoft et al., 2011; Mangubhai et al., 2015). Oleh karena itu, konservasi ekosistem terumbu karang di KKP berbasis hak (rights-based fisheries management) memiliki peluang keberhasilan lebih tinggi karena mendorong partisipasi nelayan, memiliki mekanisme untuk membatasi nelayan luar, serta membantu mendistribusikan manfaat sumber daya perikanan secara merata ke masyarakat yang hidup di dalam KKP (McClanahan et al., 2005).

Salah satu bentuk dari pengelolaan perikanan berbasis hak adalah territorial use rights for fisheries (TURF) yang didefinisikan sebagai bentuk hak spasial yang diberikan secara eksklusif kepada sekelompok masyarakat untuk memanfaatkan sumber daya alam di suatu kawasan dengan batasan spasial yang jelas (Christy, 1982). TURF dapat dikombinasikan dengan KKP dan disebut sebagai TURF-Reserve. TURFReserve terdiri dari dua jenis status kawasan, yaitu kawasan TURF dan kawasan marine reserve. TURF adalah kawasan yang mengizinkan aktivitas pemanfaatan sumber daya yang hanya boleh dilakukan oleh penerima hak eksklusif, sedangkan kawasan marine reserve, atau juga disebut dengan notake zone di dalam nomenklatur KKP, adalah kawasan yang tidak mengizinkan segala bentuk aktivitas ekstraksi sumber daya (Afflerbach et al., 2014; Gelcich \& Donlan, 2015). Dengan demikian, aktivitas perikanan karang di TURF-Reserve menjadi kegiatan yang terbatas atau tidak bersifat open access.
Teluk Mayalibit terletak di Pulau Waigeo, Kabupaten Raja Ampat, Provinsi Papua Barat. Masyarakat Teluk Mayalibit adalah masyarakat adat yang bergantung kepada sumber daya alam dari kebun dan laut untuk memenuhi kebutuhan hidup setiap hari. Masyarakat adat yang berprofesi sebagai nelayan di Teluk Mayalibit adalah nelayan skala kecil yang mengandalkan hidupnya pada ikan karang untuk konsumsi pribadi (artisanal/subsistence fisheries). Upaya pengelolaan sumber daya perairan secara formal di Teluk Mayalibit berawal dari ditetapkannya Teluk Mayalibit sebagai Kawasan Konservasi Perairan Daerah (KKPD) Wilayah II dari lima melalui Keputusan Menteri Kelautan dan Perikanan No. 36/2014. Masyarakat adat Teluk Mayalibit memiliki tradisi dalam mengelola sumber daya perikanan secara berkelanjutan melalui praktik perikanan adat, namun seiring berjalannya waktu, praktik perikanan adat semakin terkikis dari kehidupan masyarakat Teluk Mayalibit. Hal tersebut mendorong Dewan Adat Suku Maya Raja Ampat bersama dengan masyarakat adat Teluk Mayalibit mendeklarasikan Kelola Perikanan Adat (KPA) pada Februari 2017 (Rare Indonesia, 2017). KPA adalah suatu pendekatan pengelolaan sumber daya perikanan yang mengombinasikan hak ulayat laut (customary marine tenure), kearifan ekologi tradisional (traditional ecological wisdom), dan prinsip-prinsip TURF-Reserve. Deklarasi KPA Teluk Mayalibit difasilitasi oleh Unit Pelaksana Teknis Daerah Pengelolaan Kawasan Konservasi Perairan Kepulauan Raja Ampat (UPTD KKP Kep. Raja Ampat) dan dua lembaga swadaya masyarakat (LSM) yang bergerak di bidang konservasi yaitu, Rare dan Conservation International. KPA Teluk Mayalibit bertujuan untuk meningkatkan efektivitas pengelolaan perikanan karang serta upaya konservasi di KKPD Teluk Mayalibit melalui revitalisasi aturan perikanan adat dan partisipasi masyarakat adat dalam upaya pengelolaan perikanan. 
Beberapa penelitian mengenai pengelolaan perikanan berbasis hak dan TURF-Reserve di Indonesia sudah pernah dipublikasikan (Satria \& Adhuri, 2010; Halim et al., 2017; Paulangan et al., 2018; Tebay \& Manan, 2018). Hingga kini, tidak banyak penelitian yang mengkaji KPA di Indonesia secara spesifik mengingat KPA Teluk Mayalibit saja baru dideklarasikan pada awal 2017. Terdapat dua studi yang menyebutkan TURF-Reserve secara spesifik. Pertama, Irby \& Kushardanto (2018) yang menulis tentang jejaring TURF-Reserve di Selat Dampier melaporkan bahwa pendekatan yang mengombinasikan hak adat dengan KKP berhasil memberdayakan masyarakat adat melalui pengalokasian hak penangkapan ikan di KKPD Selat Dampier. Kedua, Susanto et al. (2018) melaporkan bahwa pendekatan TURF-Reserve di Teluk Kolono, yang dikenal dengan nama pengelolaan akses area perikanan (PAAP), berhasil meningkatkan kesehatan terumbu karang, pengetahuan masyarakat mengenai praktik perikanan yang berkelanjutan, dan kepatuhan masyarakat terhadap peraturan perikanan. Penelitian tentang KPA atau TURF-Reserve sangat penting dilakukan mengingat potensinya untuk meningkatkan keefektifan upaya-upaya konservasi sumber daya laut dan pesisir perlu dipertimbangkan oleh Pemerintah Indonesia.

Sejauh ini, keefektifan KPA di Teluk Mayalibit belum pernah dikaji dalam kaitan menjaga kesehatan terumbu karang. Salah satu tantangan dalam mengkaji efektivitas KPA adalah terbatasnya studi mengenai KPA dan terbatasnya data perikanan karang di Teluk Mayalibit (data-limited fisheries). Perikanan dengan data terbatas seperti KPA Teluk Mayalibit dapat menggunakan data kesehatan terumbu karang sebagai proxy untuk mengukur dampak aktivitas perikanan karang terhadap ekosistem terumbu karang serta mengukur efektivitas KPA (Karr et al., 2015; Nash \& Graham, 2016; Fox et al., 2017). Oleh karena itu, penelitian ini secara khusus mengukur keefektifan KPA dari sudut pandang kondisi kesehatan ekosistem terumbu karang yang diperlukan untuk keberlanjutan perikanan karang di Teluk Mayalibit.

\section{METODE PENELITIAN}

\subsection{Waktu dan Lokasi Penelitian}

Penelitian dilaksanakan dalam bentuk pengamatan untuk pengumpulan data pada April-September 2019 di Teluk Mayalibit, Kabupatan Raja Ampat, Provinsi Papua Barat (Gambar 1). Titik pengamatan kondisi terumbu karang dipilih berdasarkan titik pengamatan yang digunakan untuk memantau kesehatan terumbu karang sejak 2010 (Mangubhai et al., 2012). Kegiatan pemantauan kesehatan terumbu karang di Teluk Mayalibit ini merupakan kolaborasi berbagai organisasi dan universitas yang bertujuan untuk mengukur efektivitas KKPD Teluk Mayalibit. Seiring berjalannya waktu, kegiatan tersebut terus berkembang dan pengumpulan data yang lebih ekstensif dilakukan setiap dua tahun sejak 2012.

\subsection{Alat Penelitian dan Metode Pengumpulan Data}

Alat yang digunakan dalam penelitian ini adalah peralatan SCUBA, pita ukur $50 \mathrm{~m}$ sebagai transek, underwater slate, pensil, buku panduan identifikasi ikan karang oleh Allen et al. (2003), global positioning system (GPS), dan kamera. Data yang dikumpulkan di lapangan adalah kondisi ekosistem terumbu karang yang dilakukan pada 14 titik pengamatan. Penelitian ini juga memanfaatkan data kondisi terumbu karang dan ikan karang pada tahun 2014, 2016, dan 2018 yang dikumpulkan oleh Rare.

Pengumpulan data kondisi ekosistem terumbu karang menggunakan metode underwater visual census (UVC). Data bentik dikumpulkan menggunakan metode point intercept transect (PIT) dan data ikan karang dikumpulkan dengan metode transek sabuk ikan (fish belt transect). Metode PIT menggunakan transek $50 \mathrm{~m}$ dengan tiga 


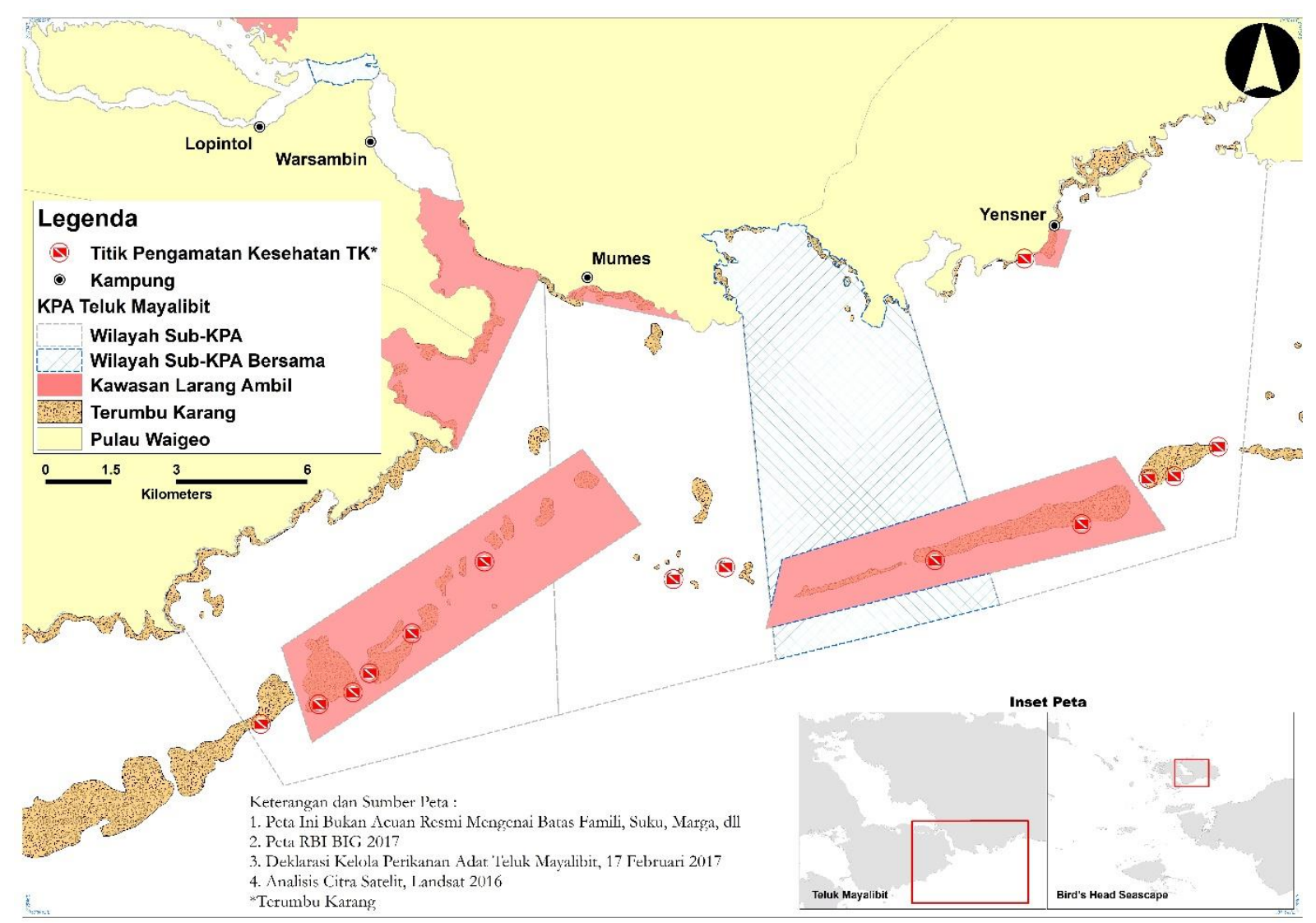

Gambar 1. Lokasi pengumpulan data di KPA Teluk Mayalibit.

replikasi di setiap titik pengamatan. Kategori bentuk hidup bentik yang berada di bawah transek dicatat dengan interval $0,5 \mathrm{~m}$. Pencatatan kategori bentuk hidup bentik dimulai pada titik $0,5 \mathrm{~m}$ dan berakhir di titik $50 \mathrm{~m}$. Metode transek sabuk ikan menggunakan transek $50 \mathrm{~m}$ dengan lima replikasi dan menggunakan dua luasan transek berdasarkan ukuran ikan yang diamati di setiap titik pengamatan. Ikan-ikan berukuran 10-35 cm dikumpulkan menggunakan transek $250 \mathrm{~m}^{2}(5 \times 50 \mathrm{~m})$, sedangkan ikan berukuran $>35 \mathrm{~cm}$ menggunakan transek $1000 \mathrm{~m}^{2}(20 \times 50 \mathrm{~m})$. Semua ikan yang berada di dalam area transek dicatat dengan rincian jenis, jumlah, dan diestimasi panjang totalnya (total length/TL), sedangkan ikan yang berada di luar area transek tidak dicatat. Transek diletakan di dasar perairan pada kedalaman 7-10 m dengan jarak antar transek replikasi sebesar 5 m (Ahmadia et al., 2013).

Pengumpulan data ikan karang difokuskan kepada beberapa famili ikan yang dapat menggambarkan kesehatan ekosistem terumbu karang serta aktivitas perikanan karang (Green \& Bellwood, 2009; Ahmadia et al., 2013). Famili tersebut dikelompokkan ke dalam enam kelompok trofik, yaitu: (a) herbivor, yang terdiri dari famili Acanthuridae, Scaridae, dan Siganidae; (b) piscivor, yang terdiri dari famili Carangidae, Haemulidae, Lethrinidae, Lutjanidae, Scombridae, Serranidae, dan Sphyraenidae; (c) invertivor, yang terdiri dari famili Balistidae, Carangidae, dan Labridae; (d) detritivor, yang terdiri dari famili Acanthuridae; (e) omnivor, yang terdiri dari famili Balistidae dan Labridae; serta (f) planktivor, yang terdiri dari famili Acanthuridae dan Scombridae. 


\subsection{Analisis Data}

\subsubsection{Penilaian Parameter Kesehatan Terumbu Karang}

Data primer dan sekunder dianalisis menggunakan pendekatan analisis deskriptif. Data bentik dan ikan karang untuk setiap titik pengamatan dirata-rata berdasarkan jumlah replikasi. Hasil analisis dibandingkan secara temporal dan secara spasial antar status kawasan di KPA yaitu, kawasan TURF yang disebut sebagai kawasan pemanfaatan dan kawasan marine reserve yang disebut sebagai kawasan larang ambil (KLA).

Data bentik dianalisis menjadi persentase tutupan berdasarkan kategori bentuk hidup (life form) bentik (Ahmadia et al., 2013).

$$
P L F_{i}=\left(\frac{L F_{i}}{\text { Total Titik }}\right) \times 100 \%
$$

Keterangan: $P L F_{i}$ adalah persentase tutupan bentuk hidup bentik- $i(\%), L f_{i}$ adalah jumlah titik untuk bentik- $i$ dalam satu transek, dan Total Titik adalah jumlah total titik dalam satu transek (100 titik).

Persentase tutupan makroalga dan karang keras hidup hasil analisis kemudian dibandingkan menjadi nilai rasio makroalga: karang keras hidup (McClanahan et al., 2011).

$$
\text { ma: } h c=\frac{P L F_{m a}}{P L F_{h e}} \text {. }
$$

Keterangan: ma: $h c$ adalah rasio tutupan makroalga dibandingkan dengan tutupan karang keras hidup, $P L F_{m a}$ adalah persentase tutupan makroalga, dan $P L F_{h c}$ adalah persentase tutupan karang keras hidup.

Ikan karang yang berada di dalam transek dihitung jumlahnya per spesies kemudian dibagi berdasarkan luasan transek sabuk ikan (Ahmadia et al., 2013).

$D_{i}=\left(\frac{x_{i}}{A}\right) \times 10000$

Keterangan: $D_{i}$ adalah kepadatan ikan-i per hektar (individu/ha), $x_{i}$ adalah jumlah individu ikan-i dalam satu transek, dan $A$ adalah luas transek sabuk ikan berdasarkan ukuran ikan yang diamati $\left(\mathrm{m}^{2}\right)$.

Panjang ikan karang yang tercatat dikonversi menjadi berat dengan menggunakan konstanta bobot dari Kulbicki et al. (2005) dan FishBase oleh Froese \& Pauly (2018).

$$
W=\frac{\left(a \times L^{b}\right)}{1000}
$$

Keterangan: $W$ adalah berat individu ikan $(\mathrm{kg}), L$ adalah panjang total ikan $(\mathrm{cm}), a$ dan $b$ adalah konstanta bobot ikan.

Berat ikan karang yang diperoleh dari hasil konversi panjang diubah menjadi biomassa ikan per satuan luas area (Ahmadia et al., 2013).

$$
B_{i}=W \times D_{i}
$$

Keterangan: $B_{i}$ adalah biomassa individu ikan karang per hektar (kg/ha), $W$ adalah berat individu ikan $(\mathrm{kg})$, dan $D_{i}$ adalah kepadatan ikan-i per hektar (individu/ha).

Densitas ikan karang dibagi berdasarkan kawasan pemanfaatan dan KLA, kemudian densitas ikan di kedua kawasan tersebut dibandingkan menjadi rasio densitas ikan karang di KPA (McDonald et al., 2018).

$R D=\frac{D_{k p}}{D_{k l a}}$

Keterangan: $R D$ adalah rasio densitas ikan karang di KPA (fished: unfished density ratio), $D_{k p}$ adalah densitas ikan karang di kawasan pemanfaatan (individu/ha), dan $D_{k l a}$ adalah densitas ikan karang di KLA (individu/ha).

Biomassa ikan karang dibagi berdasarkan kawasan pemanfaatan dan KLA, kemudian biomassa di kedua kawasan tersebut dibandingkan menjadi rasio biomassa ikan karang di KPA (McDonald et al., 2018). 
$R B=\frac{B_{k p}}{B_{k l a}}$

Keterangan: $R B$ adalah rasio biomassa ikan karang di KPA (fished: unfished biomass ratio), $B_{k p}$ adalah biomassa ikan karang di kawasan pemanfaatan (kg/ha), dan $B_{k l a}$ adalah biomassa ikan karang di KLA (kg/ha).

Biomassa ikan karang dari kelompok trofik herbivor dibandingkan dengan biomassa total ikan karang untuk mendapatkan nilai proporsi biomassa kelompok trofik herbivor di KPA Teluk Mayalibit (MacNeil et al., 2015).

$$
B P_{\text {herb }}=\frac{T G B_{\text {herb }}}{\mathbb{\Sigma} B_{i}}
$$

Keterangan: $B P_{h e r b}$ adalah proporsi biomassa kelompok trofik herbivor, $T G B_{\text {herb }}$ adalah biomassa kelompok trofik hebivor $(\mathrm{kg} / \mathrm{ha})$, dan $B_{i}$ adalah biomassa individu ikan karang per hektar (kg/ha).

\subsubsection{Penentuan Status Ekosistem Terumbu Karang}

Kondisi ekosistem terumbu karang diukur menggunakan parameter kesehatan terumbu karang yang terdiri dari lima indikator. Lima indikator tersebut diadopsi dan dimodifikasi dari Mascia et al. (2017) yang awalnya digunakan untuk mengukur efektivitas KKP. McDonald et al. (2018) mengembangkan indikator tersebut menjadi suatu perangkat untuk menilai pengelolaan perikanan adaptif dengan data terbatas menggunakan data kesehatan terumbu karang yang dikompilasi dari berbagai studi. Penelitian ini mengadopsi pendekatan yang sama dan menggunakan indikator kesehatan terumbu karang dengan ambang batas ekologi (ecological threshold) untuk mengukur kondisi ekosistem terumbu karang serta efektivitas KPA dalam menjaga kesehatan terumbu karang (Tabel 1).

Setiap indikator memiliki ambang batas ekologi untuk menentukan kondisi ekosistem terumbu karang yang mencerminkan efektivitas KPA Teluk Mayalibit sebagai suatu pendekatan pengelolaan perikanan karang. Ambang batas ekologi berfungsi sama seperti titik referensi (reference point) yang sering digunakan untuk menentukan status stok perikanan. Setiap ambang batas ekologi memiliki ambang batas bawah (lower threshold) dan ambang batas atas (upper threshold). Jika nilai indikator lebih kecil daripada nilai ambang batas bawah, maka kondisi ekosistem terumbu karang dikatakan tidak sehat dan aktivitas perikanannya tidak berkelanjutan. Jika nilai indikator berada di antara nilai ambang batas bawah dan atas, maka kondisi ekosistem terumbu karang dikatakan sedang/moderat. Jika nilai

Tabel 1. Parameter kesehatan terumbu karang.

\begin{tabular}{|c|c|c|}
\hline Indikator & Ambang Batas Ekologi & Sumber \\
\hline $\begin{array}{l}\text { Rasio tutupan } \\
\text { makroalga (ma): karang } \\
\text { keras hidup (hc) }\end{array}$ & $\begin{array}{l}\text { Ambang Batas Bawah: 0,3 } \\
\text { Ambang Batas Atas: 0,5 }\end{array}$ & McClanahan et al. (2011) \\
\hline Biomassa ikan karang & $\begin{array}{l}\text { Ambang Batas Bawah: } 300 \mathrm{~kg} / \mathrm{ha} \\
\text { Ambang Batas Atas: } 600 \mathrm{~kg} / \mathrm{ha}\end{array}$ & McClanahan et al. (2011) \\
\hline $\begin{array}{l}\text { Rasio fished: unfished } \\
\text { densitas ikan karang }\end{array}$ & $\begin{array}{l}\text { Ambang Batas Bawah: 0,2 } \\
\text { Ambang Batas Atas: 0,6 }\end{array}$ & $\begin{array}{l}\text { McGilliard et al. (2010) } \\
\text { Fujita } \text { et al. (2014) } \\
\text { Babcock \& MacCall (2011) }\end{array}$ \\
\hline $\begin{array}{l}\text { Rasio fished: unfished } \\
\text { biomassa ikan karang } \\
\text { Proporsi biomassa ikan } \\
\text { herbivor }\end{array}$ & $\begin{array}{l}\text { Ambang Batas Bawah: 0,25 } \\
\text { Ambang Batas Atas: 0,5 } \\
\text { Ambang Batas Bawah: 0,3 } \\
\text { Ambang Batas Atas: 0,4 }\end{array}$ & $\begin{array}{l}\text { McClanahan et al. (2011) } \\
\text { Karr } \text { et al. }(2015) \\
\text { MacNeil et al. (2015) }\end{array}$ \\
\hline
\end{tabular}


indikator berada di atas nilai ambang batas atas, maka kondisi ekosistem terumbu karang dikatakan sehat dan aktivitas perikanannya berkelanjutan.

Indikator rasio makroalga: karang keras hidup adalah satu-satunya indikator yang menggunakan nilai ambang batas terbalik (inverted). Jika nilai rasio makroalga: karang keras hidup lebih kecil daripada nilai ambang batas bawahnya, maka ekosistem terumbu karang didominasi oleh karang keras hidup. Sebaliknya, jika nilai rasio makroalga: karang keras hidup lebih besar dari nilai ambang batas atasnya, maka ekosistem terumbu karang didominasi oleh makroalga, yang menunjukkan kondisi ekosistem terumbu karang yang tidak sehat. Namun, jika nilai rasio makroalga: karang keras hidup berada di antara nilai ambang batas bawah dan ambang batas atas, diartikan bahwa kondisi bentik berada di kondisi yang optimal.

\section{HASIL DAN PEMBAHASAN}

\subsection{Makroalga dan Karang Keras Hidup}

Nilai rasio makroalga: karang keras hidup di kawasan pemanfaatan lebih kecil daripada nilai ambang batas bawah, hal ini menunjukkan bahwa karang keras hidup adalah bentuk hidup bentik yang mendominasi ekosistem terumbu karang di kawasan pemanfaatan. Kondisi bentik yang optimal hanya terjadi pada 2018 karena nilai rasionya berada di antara nilai ambang batas bawah dan atas. Kondisi yang sebaliknya terjadi pada KLA dengan nilai rasio makroalga: karang keras hidup yang meningkat sampai melebihi nilai ambang batas atas, sehingga dapat diartikan bahwa makroalga lebih dominan daripada karang keras hidup di KLA. Jika dibandingkan, kondisi bentik di kawasan pemanfaatan lebih sehat dibandingkan dengan KLA karena tren rasio makroalga: karang keras hidup di kawasan pemanfaatan menunjukkan perbaikan kondisi bentik (Gambar 2).

Nilai rasio makroalga: karang keras hidup di kawasan pemanfaatan dan KLA belum mencapai nilai yang optimal, kondisi ini dapat diartikan sebagai kesehatan terumbu karang yang tergolong sedang/moderat. Kondisi bentik yang moderat ini menunjukkan bahwa KPA di Teluk Mayalibit masih perlu ditingkatkan efektivitasnya dalam menjaga kesehatan terumbu karang, karena menurut Pratchett et al. (2011),

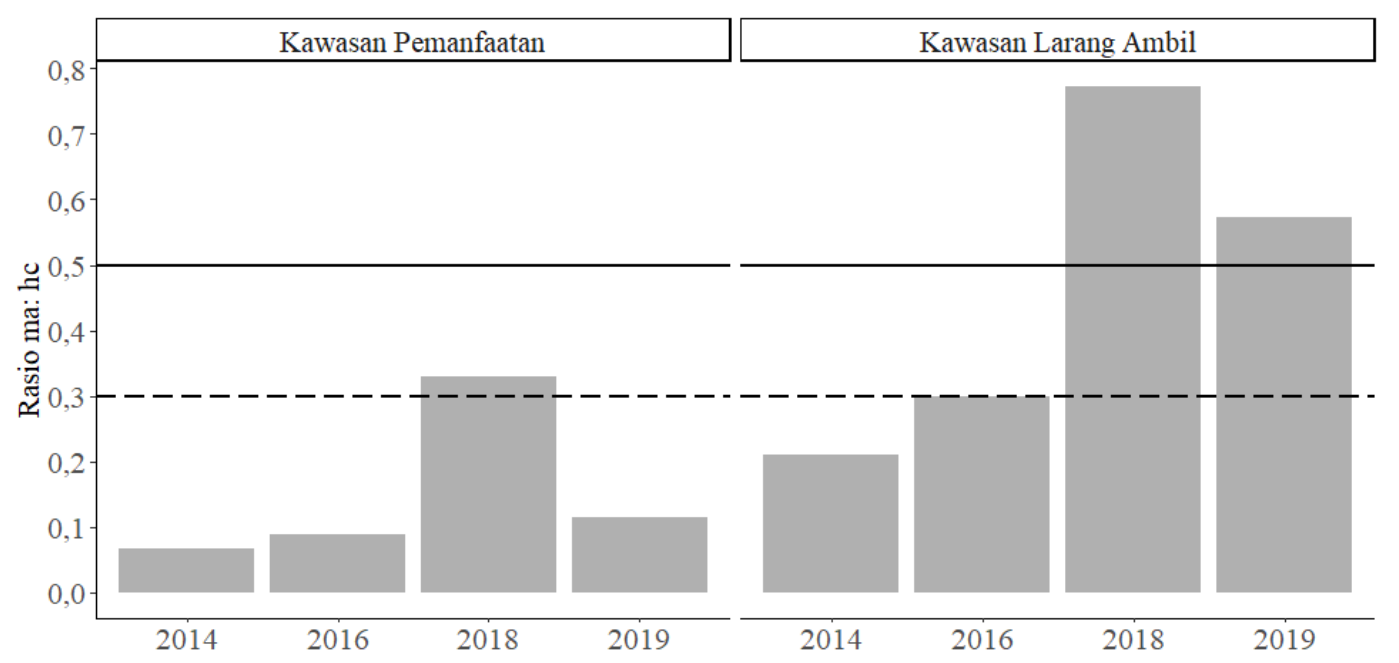

Gambar 2. Rasio tutupan makroalga (ma): karang keras hidup (hc) berdasarkan status kawasan di KPA. Garis hitam horizontal menunjukkan ambang batas atas. Garis hitam horizontal putus-putus menunjukkan ambang batas bawah. 
ekosistem terumbu karang yang sehat tidak hanya terdiri dari karang keras hidup, tetapi juga makroalga. Namun, makroalga tidak boleh dominan di dalam ekosistem terumbu karang agar rezim terumbu karang tidak bergeser menjadi rezim terumbu alga (algal reef). Nilai rasio makroalga: karang keras hidup di kawasan pemanfaatan menunjukkan peran KPA dalam menjaga kestabilan rezim terumbu karang. Sebaliknya, nilai rasio makroalga: karang keras hidup di KLA mengindikasikan adanya aktivitas perikanan di kawasan tersebut, seperti yang disebutkan oleh McClanahan et al. (2011) bahwa, peningkatan tutupan makroalga dapat menjadi indikator pertama dari adanya aktivitas perikanan di suatu kawasan.

Kondisi bentik di KLA yang lebih didominasi oleh makroalga juga menunjukkan bahwa ekosistem terumbu karang di KLA lebih sensitif terhadap aktivitas perikanan dibandingkan dengan kawasan pemanfaatan, seperti yang disebutkan oleh Graham et al. (2009) bahwa, kondisi bentik di suatu kawasan juga dapat menggambarkan sensitivitas kawasan tersebut terhadap tekanan perikanan. KLA yang lebih sensitif terhadap tekanan perikanan menunjukkan bahwa upaya pengawasan terhadap aktivitas perikanan di KLA yang dilakukan oleh nelayan luar maupun nelayan lokal menjadi penting agar sumber spillover dan kesehatan ekosistem terumbu karang tetap terjaga.

\subsection{Densitas dan Biomassa Ikan Karang}

Nilai biomassa ikan karang di kawasan pemanfaatan pada awalnya berada di atas nilai ambang batas atas, namun, nilai biomassa ikan karang mengalami penurunan, sehingga pada 2019 nilainya berada di antara nilai ambang batas bawah dan atas. Di KLA, nilai biomassa ikan karang sejak 2012 sampai 2019 selalu lebih besar daripada nilai ambang batas atas, akan tetapi, tren nilai biomassa ikan karang juga mengalami penurunan (Gambar 3).

Nilai biomassa ikan karang di kawasan pemanfaatan menunjukkan kondisi ekosistem terumbu karang yang moderat, sedangkan biomassa ikan karang di KLA menunjukkan kondisi ekosistem terumbu karang yang sehat. Kondisi ini mengindikasikan bahwa ekosistem terumbu karang di KLA relatif lebih sehat

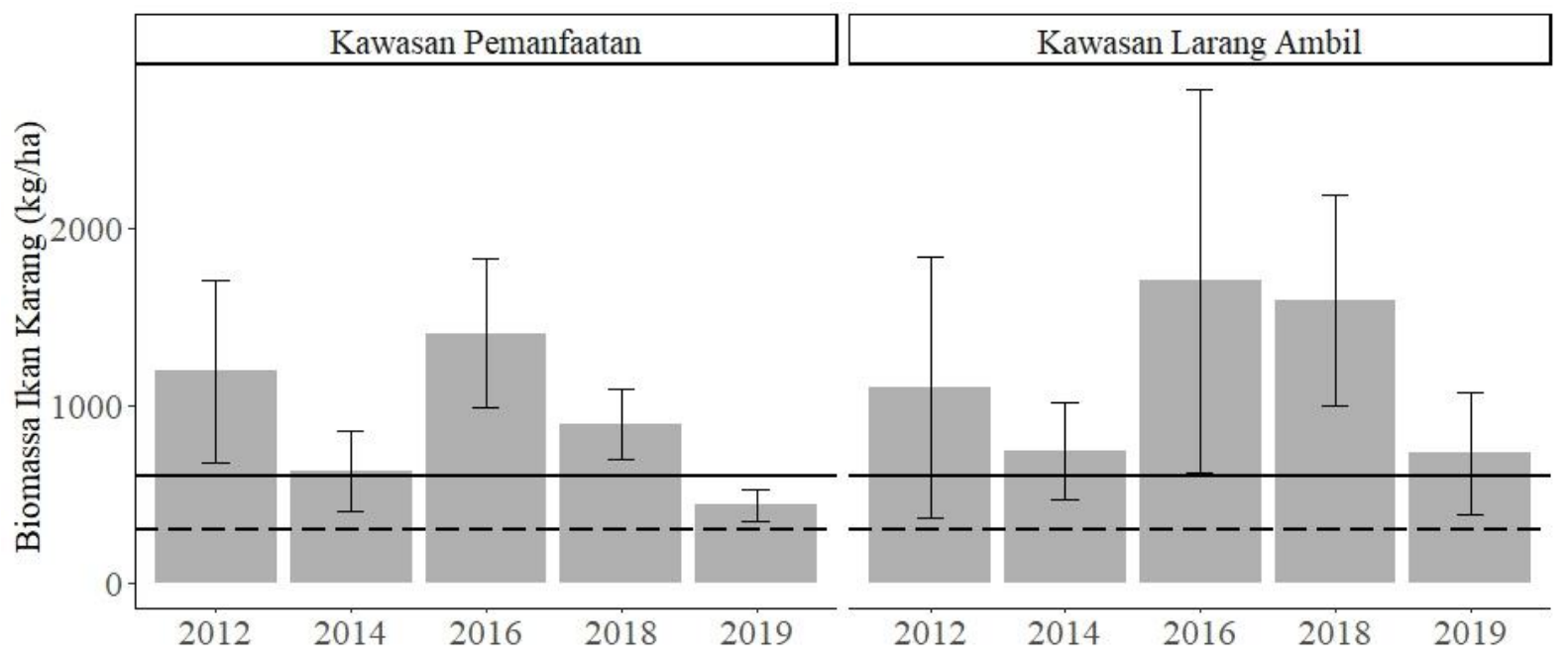

Gambar 3. Biomassa ikan karang berdasarkan status kawasan di KPA. Nilai yang ditunjukkan adalah nilai rata-rata \pm standard error. Garis hitam horizontal menunjukkan ambang batas atas. Garis hitam horizontal putus-putus menunjukkan ambang batas bawah. 
dibandingkan dengan kawasan pemanfaatan. Temuan ini sejalan dengan yang disebutkan oleh Claudet et al. (2011), bahwa nilai biomassa ikan karang di KLA umumnya lebih besar daripada kawasan pemanfaatan karena KLA terlindungi dari aktivitas penangkapan ikan. Namun, jika dilihat dari tren biomassa ikan karang, biomassa ikan karang di KLA dan kawasan pemanfaatan sama-sama mengalami penurunan. Penurunan nilai biomassa ikan karang di kawasan pemanfaatan yang masih dalam kondisi moderat mengindikasikan peran karang keras hidup yang mampu menahan laju penurunan biomassa ikan karang di kawasan pemanfaatan. Sebaliknya, biomassa ikan karang di KLA yang diharapkan stabil ternyata juga menunjukkan penurunan. Penurunan ini diduga disebabkan oleh tutupan makroalga yang lebih dominan di KLA, sehingga menjadi indikasi bahwa upaya perlindungan KLA belum berjalan maksimal.

Berdasarkan kondisi biomassa ikan karang, terlihat bahwa KPA memiliki peran dalam mengompensasi tekanan perikanan dan memperlambat laju penurunan kesehatan terumbu karang, karena kondisi biomassa ikan karangnya masih tergolong moderatsehat. Keberadaan KLA di dalam KPA berperan sebagai sumber spillover ikan karang ke kawasan pemanfaatan. Hal ini sejalan dengan yang disebutkan oleh McClanahan et al. (2011) bahwa, marine reserve, dalam hal ini adalah $\mathrm{KLA}$, dapat meningkatkan resiliensi ekosistem terumbu karang dengan menyediakan habitat tempat berlindung bagi individu ikan karang yang berukuran lebih besar dan sudah matang gonad.

Nilai rasio fished: unfished densitas ikan karang mengalami penurunan jika dibandingkan dengan nilai rasio pada 2012, akan tetapi, nilainya tidak pernah lebih kecil daripada nilai ambang batas bawah. Nilai rasio fished: unfished densitas ikan karang kemudian meningkat pada 2019 dan hampir mencapai nilai ambang batas atas. Hal tersebut menunjukkan adanya indikasi awal pemulihan densitas ikan karang di KPA Teluk Mayalibit. Nilai rasio fished: unfished biomassa ikan karang juga mengalami penurunan jika dibandingkan dengan nilai pada 2012, walaupun nilainya selalu lebih besar daripada nilai ambang batas atas (Gambar 4).

Tren nilai rasio fished: unfished pada densitas dan biomassa ikan karang yang menurun mengindikasikan kondisi ekosistem terumbu karang yang moderat-sehat. Hal ini menunjukkan bahwa tekanan perikanan di Teluk Mayalibit semakin meningkat dari tahun ke tahun, seperti yang disebutkan oleh Karr et al. (2015) bahwa, kondisi ekosistem terumbu karang yang moderat menjadi tandatanda awal perubahan ekosistem terumbu karang akibat adanya aktivitas perikanan. Di sisi lain, meningkatnya nilai rasio fished: unfished densitas dan biomassa pada 2019 menunjukkan peran KPA dalam membantu

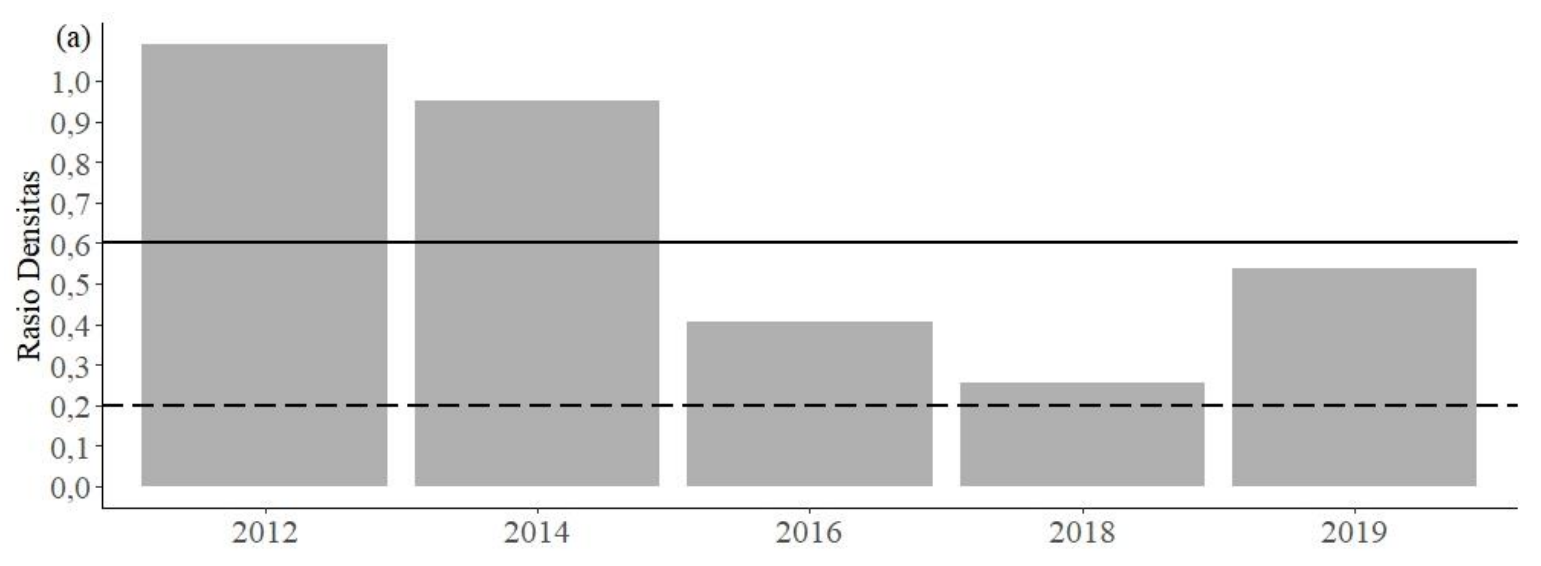




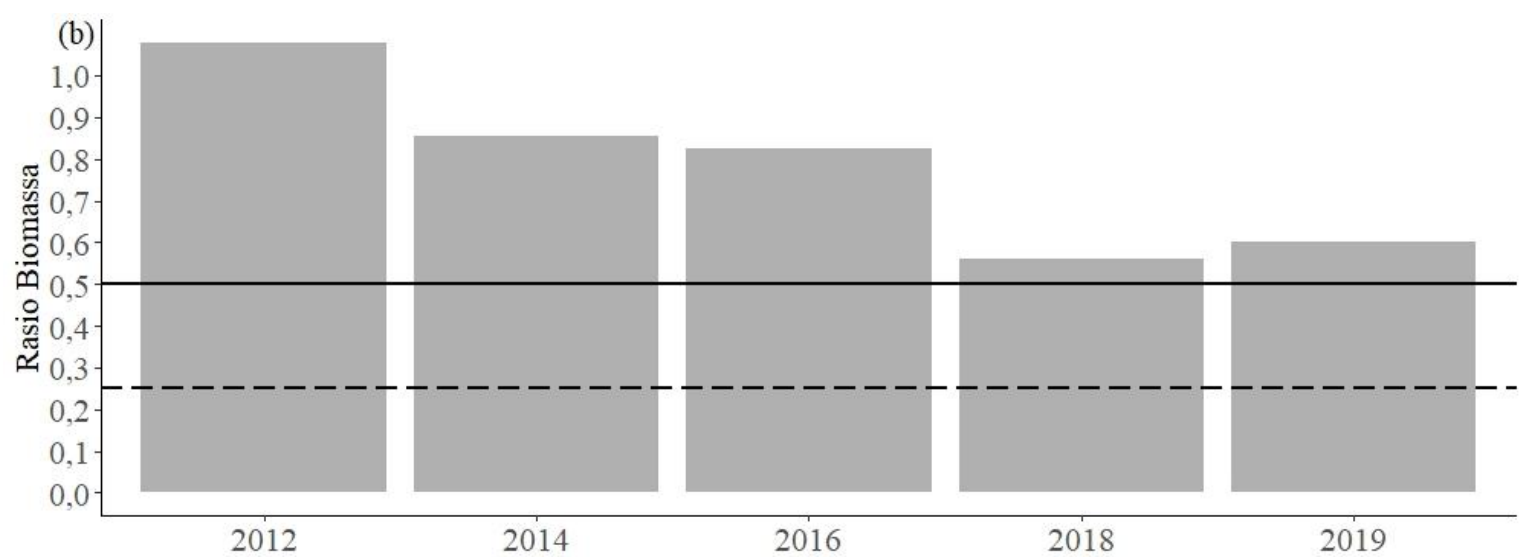

Gambar 4. Rasio fished: unfished (a) densitas dan (b) biomassa ikan karang di KPA. Garis hitam horizontal menunjukkan ambang batas atas. Garis hitam horizontal putusputus menunjukkan ambang batas bawah.

pemulihan kesehatan ekosistem terumbu karang di Teluk Mayalibit. Nilai rasio fished: unfished densitas yang meningkat mendekati nilai ambang batas atas mengindikasikan proses pemulihan biomassa ikan karang melalui spillover ikan karang dari KLA menuju kawasan pemanfaatan. Melalui praktik perikanan adat yang berkelanjutan, KPA diharapkan dapat menahan laju tekanan perikanan karang dan membantu memulihkan biomassa ikan karang, sehingga nilai rasio fished: unfished dapat dan selalu melebihi nilai ambang batas atas.

\subsection{Biomassa Ikan Herbivor}

Nilai proporsi biomassa ikan herbivor di kawasan pemanfaatan berfluktuasi dari tahun ke tahun dan mengalami peningkatan pada 2019, sehingga nilainya lebih besar daripada nilai ambang batas atas. Kondisi yang sedikit berbeda terjadi pada nilai proporsi biomassa ikan herbivor di KLA yang mengalami penurunan sampai pada 2018 kemudian meningkat pada 2019, sehingga nilainya lebih besar daripada nilai ambang batas atas (Gambar 5). Kondisi ini menunjuk-kan biomassa ikan herbivor di kawasan pemanfaatan lebih stabil dibandingkan dengan biomassa ikan herbivor di KLA yang baru menunjukkan tanda-tanda pemulihan pada 2019.
Fluktuasi kelompok trofik ikan karang terjadi karena adanya aktivitas pemanfaatan di dalam suatu kawasan (Glynn, 2008). Kondisi tersebut terjadi pada kelompok trofik ikan herbivor di Teluk Mayalibit yang mengindikasikan peningkatan tekanan perikanan karang. Namun, KPA mampu membantu proses pemulihan ikan herbivor karena nilai proporsi biomassa di kawasan pemanfaatan dan KLA lebih besar daripada nilai ambang batas atas pada 2019. Peran KPA dalam membantu pengelolaan perikanan karang sejalan dengan yang disebutkan oleh McClanahan (2008) bahwa, upaya pengelolaan ikan herbivor yang menjadi target perikanan dapat membantu menjaga kesehatan ekosistem terumbu karang. Green \& Bellwood (2009) menyebutkan bahwa ikan herbivor dapat menjadi indikator kesehatan terumbu karang karena keberadaan ikan herbivor dapat mengontrol pertumbuhan makroalga yang berkompetisi dengan karang keras hidup. Nilai proporsi biomassa ikan herbivor di kawasan pemanfaatan yang lebih tinggi daripada KLA mengonfirmasi kondisi bentik di kawasan pemanfaatan yang lebih didominasi oleh karang keras hidup, karena pertumbuhan makroalga di kawasan pemanfaatan dapat dikontrol oleh ikan herbivor. 


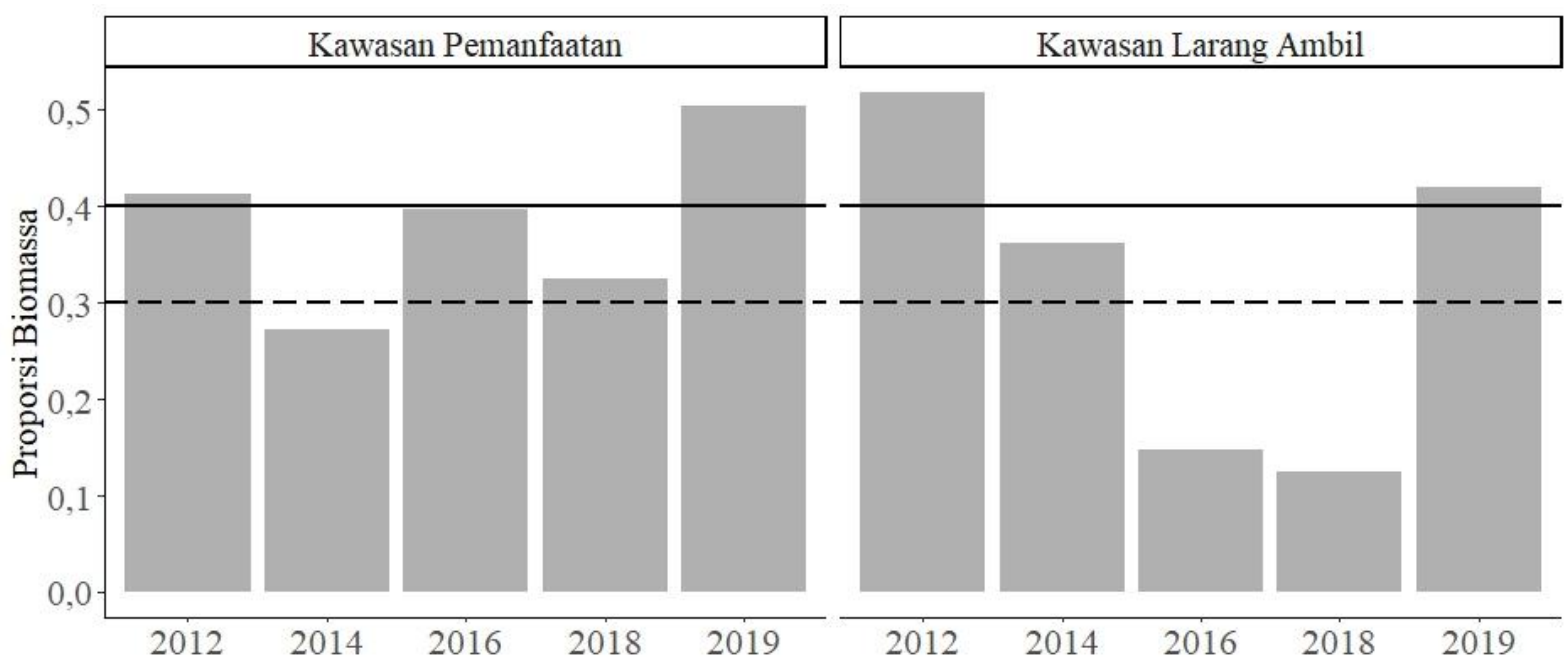

Gambar 5. Proporsi biomassa ikan herbivor berdasarkan status kawasan di KPA. Garis hitam horizontal menunjukkan ambang batas atas. Garis hitam horizontal putus-putus menunjukkan ambang batas bawah.

\subsection{Status Kesehatan Terumbu Karang di Teluk Mayalibit}

McDonald et al. (2018) menyebutkan bahwa, mengintegrasikan berbagai macam indikator menjadi interpretasi tunggal yang menggambarkan kondisi ekosistem terumbu karang dan perikanan membutuhkan kehatihatian, khususnya ketika nilai-nilai indikator menunjukkan interpretasi yang beragam. Interpretasi status kesehatan terumbu karang di KPA Teluk Mayalibit membutuhkan pendekatan kehati-hatian (precautionary approach), karena KPA Teluk Mayalibit berlokasi di Raja Ampat. Nilai ambang batas ekologi yang tersedia dan dapat digunakan untuk mengukur kondisi ekosistem terumbu karang bersumber dari studi-studi yang berlokasi di perairan tropis secara umum dan tidak menyebutkan Raja Ampat secara spesifik, sedangkan Raja Ampat dikenal dengan kondisi ekosistem terumbu karang yang berada di atas rata-rata (Allen \& Erdmann, 2009; Veron et al., 2009).

Nilai biomassa ikan karang di KLA lebih besar dibandingkan dengan kawasan pemanfaatan, hal ini menunjukkan bahwa KPA berperan dalam mengurangi tekanan perikanan melalui keberadaan KLA. Namun, jika dilihat dari kondisi bentik, ekosistem terumbu karang di kawasan pemanfaatan lebih sehat dibandingkan dengan KLA. Kondisi ini sejalan dengan proporsi biomassa ikan herbivor yang juga lebih besar di kawasan pemanfaatan dibandingkan dengan KLA. Keberadaan ikan herbivor yang lebih melimpah di kawasan pemanfaatan membantu menjaga dominansi karang keras hidup. Sebaliknya, proporsi biomassa ikan herbivor di KLA yang masih dalam tahap pemulihan mengonfirmasi kondisi bentik di KLA yang lebih didominasi oleh makroalga. Oleh karena itu, upaya pengelolaan melalui penetapan KLA saja tidak cukup apabila tidak ada upaya tambahan untuk menjaga kelestarian ikan herbivor. Ikan herbivor yang melimpah diharapkan dapat mencegah transformasi terumbu karang menjadi terumbu alga, khususnya di KLA yang berfungsi sebagai sumber spillover dan tempat berlindung ikan karang.

Kondisi ekosistem terumbu karang di KPA Teluk Mayalibit berada pada kategori sehat, seperti yang terlihat pada nilai biomassa ikan karang dan proporsi biomassa ikan herbivor. Walaupun demikian, indikator rasio makroalga: karang keras hidup dan rasio fished: unfished ikan karang berada pada kategori sedang/moderat. Hal ini 
menunjukkan adanya tanda-tanda awal penurunan kondisi ekosistem terumbu karang, akan tetapi, penurunannya belum mengkhawatirkan. Berdasarkan kondisi ekosistem terumbu karang yang sehat, KPA dapat dikatakan efektif dalam menjaga kesehatan ekosistem terumbu karang di Teluk Mayalibit. KPA Teluk Mayalibit dapat menjadi komplementer dari KKPD Teluk Mayalibit dalam menjaga kondisi ekosistem terumbu karang, membantu upaya konservasi, serta upaya pengelolaan sumber daya perikanan karang.

\section{KESIMPULAN}

Ekosistem terumbu karang di Teluk Mayalibit berada dalam kondisi yang sehat dan aktivitas perikanan karangnya masih dalam batas lestari. KPA terlihat efektif dalam menjaga kondisi ekosistem terumbu karang dan membantu upaya konservasi serta pengelolaan sumber daya perikanan karang di Teluk Mayalibit. Efektivitas KPA di Teluk Mayalibit dapat ditingkatkan melalui upaya pengelolaan ikan-ikan yang menjadi target perikanan, khususnya ikan herbivor. Efektivitas KPA juga dapat ditingkatkan melalui upaya pengawasan aktivitas perikanan, khususnya di KLA, agar peraturan perikanan adat yang sudah ditetapkan juga dipatuhi. Pengawasan ini dapat menjadi upaya pengelolaan kolaboratif antara masyarakat adat Teluk Mayalibit dengan UPTD KKP Kep. Raja Ampat.

\section{UCAPAN TERIMA KASIH}

Peneliti mengucapkan terima kasih kepada pembimbing penelitian, UPTD KKP Kep. Raja Ampat (Syafri, Patris Baworo, Imanuel Mofu, Elvis Mambraku, Hosea Daam, dan Yakob Mambrasar), Rare (Hari Kushardanto, Katherina Tjandra, Raymond Jakub, Nursyam Dwi Vrandi, dan Wahid Suherfian), IPB University, dan teman-teman SPL 2017 yang telah memberikan dukungan dalam penelitian dan penulisan naskah ini.

\section{DAFTAR PUSTAKA}

Afflerbach, J.C., S.E. Lester, D.T. Dougherty, \& S.E. Poon. 2014. A global survey of "TURF-Reserve", Territorial User Rights for Fisheries coupled with marine reserves. Global Ecology and Conservation, 2: 97-106. https://doi.org/10.1016/j.gecco.2014.0 8.001

Ahmadia, G.N., J.R. Wilson, \& A.L. Green. 2013. Coral reef monitoring protocol for assessing marine protected areas in the Coral Triangle. Coral Triangle Support Partnership. Jakarta. 47 p.

Allen, G., R. Steene, P. Humann, \& N. DeLoach. 2003. Reef fish identification: Tropical Pacific. New World Publication, Inc. Florida. 484 p.

Allen, G.R. \& M.V. Erdmann. 2009. Reef fishes of the Bird's Head Peninsula, West Papua, Indonesia. Check List, 5(3): 587-628. https://doi.org/10.15560/5.3.587

Babcock, E.A. \& A.D. MacCall. 2011. How useful is the ratio of fish density outside versus inside no-take marine reserve as a metric for fishery management control rules?. Canadian J. of Fisheries and Aquatic Sciences, 68(2): 343-359.

https://doi.org/10.1139/F10-146

Christy, F.T. Jr. 1982. Territorial use rights in marine fisheries: Definitions and conditions. FAO Fisheries Technical Paper, 227: 10.

http://ledhyane.lecture.ub.ac.id/files/2 013/02/Territorial-use-rights-inmarine-fisheries-christy-1982.pdf

Claudet, J., P. Guidetti, D. Mouillot, N.T. Shears, \& F. Micheli. 2011. Ecology ecological effects of marine protected areas: Conservation, restoration, and functioning. In: Claudet, J., (eds). Marine protected areas: A multidisciplinary approach. Cambridge University Press. 
Cambridge.

https://doi.org/10.1017/CBO9781139 049382.005

Fox, H.E., M.D. Barnes, G.N. Ahmadia, G. Kao, L. Glew, K. Haisfield, N.I. Hidayat, C.L. Huffard, L. Katz, S. Mangubhai, \& Purwanto. 2017. Generating actionable data for evidence-based conservation: The global center of marine biodiversity as a case study. Biological Conservation, 210: 299-309.

https://doi.org/10.1016/j.biocon.2017. 04.025

Froese, R. \& D. Pauly. 2018. FishBase. World Wide Web Electronic Publication. www.fishbase.org

Fujita, R., D.J. Thornhill, K. Karr, C.H. Cooper, \& L.E. Dee. 2014. Assessing and managing data-limited ornamental fisheries in coral reefs. Fish and Fisheries, 15(4): 661-675. https://doi.org/10.1111/faf.12040

Gelcich, S. \& C.J. Donlan. 2015. Incentivizing biodiversity conservation in artisanal fishing communities through territorial user rights and business model innovation. Conservation Biology, 29(4): 10761085. https://doi.org/10.1111/cobi.12477

Glynn, P.W. 2008. Food-web structure and dynamics of Eastern Tropical Pacific Coral Reefs: Panama and Galapagos Islands. In: McClanahan, T.R. \& G.M. Branch (eds). Food webs and the dynamics of marine reefs. Oxford University Press. New York. 185-208 pp.

https://doi.org/10.1093/acprof:oso/97 80195319958.003.0008

Graham, N.A.J., S.K. Wilson, M.S. Pratchett, N.V.C. Polunin, \& M.D. Spalding. 2009. Coral mortality versus structural collapse as drivers of corallivorous butterflyfish decline. Biodiversity and Conservation, 18: 3325-3336. https://doi.org/10.1007/s10531-0099633-3

Green, A.L. \& D.R. Bellwood. 2009. Monitoring functional groups of herbivorous reef fishes as indicators of coral reef resilience: A practical guide for coral reef managers in the Asia Pacific Region. IUCN. Switzerland. $70 \mathrm{p}$.

https://www.researchgate.net/publicat ion $/ 237411023$

Halim, A., B. Wiryawan, N.R. Loneragan, M.F.A. Sondita, A. Hordyk, D.S. Adhuri, T.R. Adi, \& L. Adrianto. 2017. Konsep hak pengelolaan perikanan sebagai alat pengelolaan perikanan berkelanjutan di Indonesia. J. Kebijakan Perikanan Indonesia, 9(1): 11-20.

https://doi.org/10.15578/jkpi.9.1.2017 .11-20

Irby, S.H. \& H. Kushardanto. 2018. Rightsbased management in Indonesia's Dampier Strait: Blending customary rights and MPAs to create the world's largest comprehensive TURF+Reserve Network. FAO Fisheries and Aquaculture Proceedings No. 64, Rome.

http://www.fao.org/fishery/static/tenu re-user-rights/root/volume1/C14.pdf

Jentoft, S., R. Chuenpagdee, \& J.J. PascualFernandez. 2011. What are MPAs for: On goal formation and displacement. Ocean and Coastal Management, 54(1): 75-83. https://doi.org/10.1016/j.ocecoaman.2 010.10 .024

Karr, K.A., R. Fujita, B.S. Halpern, C.V. Kappel, L. Crowder, K.A. Selkoe, P.M. Alcolado, \& D. Rader. 2015. Thresholds in Caribbean coral reefs: Implications for ecosystem-based fishery management. J. of Applied Ecology, 52(2): 402-412. https://doi.org/10.1111/13652664.12388 
Kulbicki, M., N. Guillemot, \& M. Amand. 2005. A general approach to lengthweight relationships for New Caledonian lagoon fishes. Cybium, 29(3): 235-252. https://sficybium.fr/en/node/1297

MacNeil, M.A., N.A.J. Graham, J.E. Cinner, S.K. Wilson, I.D. Williams, J. Maina, S. Newman, A.M. Friedlander, S. Jupiter, N.V.C. Polunin, \& T.R. McClanahan. 2015. Recovery potential of the world's coral reef fishes. Nature, 520: 341-344. https://doi.org/10.1038/nature14358

Mangubhai, S., M.V. Erdmann, J.R. Wilson, C.L. Huffard, F. Ballamu, N.I. Hidayat, C. Hitipeuw, M.E. Lazuardi, Muhajir, D. Pada, G. Purba, C. Rotinsulu, L. Rumetna, K. Sumolang, \& W. Wen. 2012. Papuan Bird's Head Seascape: Emerging threats and challenges in the global center of marine biodiversity. Marine Pollution Bulletin, 64(11): 2279-2295. https://doi.org/10.1016/j.marpolbul.20 12.07.024

Mangubhai, S., J.R. Wilson, L. Rumetna, Y. Maturbongs, \& Purwanto. 2015. Explicitly incorporating socioeconomic criteria and data into marine protected area zoning. Ocean and Coastal Management, 116: 523529.

https://doi.org/10.1016/j.ocecoaman.2 015.08.018

Mascia, M.B., H.E. Fox, L. Glew, G.N. Ahmadia, A. Agrawal, M. Barnes, X. Basurto, I. Craigie, E. Darling, J. Geldmann, D. Gill, S.H. Rice, O.P. Jensen, S.E. Lester, P. McConney, P.J. Mumby, M. Nenadovic, J.E. Parks, R.S. Pomeroy, \& A.T. White. 2017. A novel framework for analyzing conservation impacts: Evaluation, theory, and marine protected areas. Annals of the New York Academy of Sciences, 1399(1): 93-115. https://doi.org/10.1111/nyas.13428

McClanahan, T., J. Davies, \& J. Maina. 2005. Factors influencing resource users and managers' perceptions towards marine protected area management in Kenya. Environmental Conservation, 32(1): 42-49.

https://doi.org/10.1017/S0376892904 001791

McClanahan, T.R. 2008. Food-web structure and dynamics of East African coral reefs. In: McClanahan, T.R. \& G.M. Branch (eds). Food webs and the dynamics of marine reefs. Oxford University Press. New York. 162-184 pp.

https://doi.org/10.1093/acprof:oso/97 80195319958.003.0007

McClanahan, T.R., N.A.J. Graham, M.A. MacNeil, N.A. Muthiga, J.E. Cinner, J.H. Bruggemann, \& S.K. Wilson. 2011. Critical threshold and tangible targets for ecosystem-based management of coral reef fisheries. In: Palumbi, S.R. (eds). Proceedings of the National Academy of Sciences, October 2011. PNAS, 108(41): 17230-17233. https://doi.org/10.1073/pnas.1106861 108

McDonald, G., S.J. Campbell, K. Karr, M. Clemence, P. Granados-Dieselforff, R. Jakub, T. Kartawijaya, J.C. Mueller, P. Prihatinningsih, K. Siegel, \& Y. Syaifudin. 2018. An adaptive assessment and management toolkit for data-limited fisheries. Ocean and Coastal Management, 152: 100-119. https://doi.org/10.1016/j.ocecoaman.2 017.11 .015

McGilliard, C.R., R. Hilborn, A. MacCall, A.E. Punt, \& J.C. Field. 2011. Can information from marine protected areas be used to inform control-rulebased management of small-scale, data-poor stocks?. ICES J. of Marine Science, 68(1): 201-211. 
https://doi.org/10.1093/icesjms/fsq15 1

Nash, K.L. \& N.A.J. Graham. 2016. Ecological indicators for coral reef fisheries management. Fish and Fisheries, 17(4): 1029-1054. https://doi.org/10.1111/faf.12157

Paulangan, Y.P., M.A. Al Amin, Y. Wahyudin, \& Taryono. 2018. Tiaitiki: pengetahuan lokal dan lembaga lokal untuk mendukung konservasi laut di Teluk Depapre, Provinsi Papua, Indonesia. Di dalam: Adrianto, L. et al. (eds). Bentang Laut Lesser Sunda dan Bismarck Solomon. IPB Press. Bogor. hlm 37-59.

Pratchett, M.S., A.S. Hoey, S.K. Wilson, V. Messmer, \& N.A.J. Graham. 2011. Changes in biodiversity and functioning of reef fish assemblages following coral bleaching and coral loss. Diversity, 3(3): 424-452. https://doi.org/10.3390/d3030424

Rare Indonesia. 2017. Rencana Pengelolaan dan Petunjuk Pelaksanaan Kelola Perikanan Adat Teluk Mayalibit. Rare Indonesia. Waisai. $34 \mathrm{hlm}$.

Satria, A. \& D.S. Adhuri. 2010. Pre-existing fisheries management systems in Indonesia, focusing on Lombok and Maluku. In: Ruddle, K. \& A. Satria (eds). Managing coastal and inland waters: Pre-existing aquatic management systems in Southeast Asia. Springer Publishing. Netherlands. 31-55 pp. https://doi.org/10.1007/978-90-4819555-8_2

Susanto, H.A., L. Hotra, \& M. Alfian. 2018. A managed access approach to sustain small-scale fisheries management in Southeast Sulawesi, Indonesia. FAO Fisheries and Aquaculture Proceedings No. 64, Rome.

http://www.fao.org/fishery/static/tenu re-user-rights/root/volume8/C88.pdf

Tebay, S. \& J. Manan. 2018. Eksistensi hukum wilayah adat Mamta dalam mendukung praktik Hukum Adat Manjo bagi pengelolaan sumber daya perikanan berkelanjutan di Teluk Youtefa, Jayapura, Papua. Di dalam: Adrianto, L. et al. (eds). Bentang Laut Lesser Sunda dan Bismarck Solomon. IPB Press. Bogor. hlm 85-107.

Veron, J.E.N., L.M. Devantier, E. Turak, A.L. Green, S. Kininmonth, M. Stafford-Smith, \& N. Peterson. 2009. Delineating the Coral Triangle. J. of Coral Reef Studies, 11: 91-100. https://doi.org/10.3755/galaxea.11.91

Submitted: 04 June 2021

Reviewed : 12 July 2021

Accepted : 18 August 2021

\section{FIGURE AND TABEL TITLES}

Figure 1. Location of data collection in Mayalibit Bay CFM.

Figure 2. Macroalgae ( $\mathrm{ma}$ ): hard coral (hc) ratio based on area status in CFM. Solid black horizontal line is upper threshold. Dashed black horizontal line is lower threshold.

Figure 3. Reeffish biomass based on area status in CFM. The values are presented as mean \pm standard error. Solid black horizontal line is upper threshold. Dashed black horizontal line is lower threshold.

Figure 4. Fished: unfished (a) density ratio and (b) biomass ratio of reeffish in CFM. Solid black horizontal line is upper threshold. Dashed black horizontal line is lower threshold. 
Efektivitas Kelola Perikanan Adat dalam Menjaga Status Kesehatan Terumbu Karang . . .

Figure 5. Biomass proportion of herbivore fish based on area status in CFM. Solid black horizontal line is upper threshold. Dashed black horizontal line is lower threshold.

Table 1. Reef health parameters. 